\title{
Tanguá Benach. Ancestros, tierra y andares
}

Tanguá Benach. Ancestors, land and wander

RESUMEN

Este texto trata de caminar por tanguá benach, camino ancestral del pueblo indígena Camëntsá. La autora puso las huellas; trata de organizar la palabra, narrar, otra forma de andar y hacer camino. Mientras va, viene, y en devuélvase está el misterio. Es una etnografía del camino, de la vida y de la muerte, de los ancestros y de la tierra de la que somos; es una etnografía de los andares.

Palabras clave: Tanguá benach, Camëntsá, camino, caminante, tierra, ancestros.

\section{Abstract}

This text is about walking through tanguá benach, ancestral path of the Camëntsá indigenous people. The author puts the prints; she tries to organize the words, narrate, another way of walking and making the way. While going, she comes, and the mystery is in returning. It is an ethnography of the path, of life and of death, of the ancestors and of the land we are from. It is an ethnography of the wander.

Keywords: Tanguá benach, Camëntsá, path, walker, land, ancestors.
Laura Viviana

Chaustre Fandiño

Maestra en Antropología

FLACSO Ecuador.

$\square$ lvchaustref@gmail.com

(1) ORCID: 0000-0002-9014-3245

si Google Scholar 


\section{Acbe shecuats̈ muinÿnaná \\ Mochanjenefn quem benachëng acbe bëts Taitang tmojëftseboché; mondmën jenefnam y cucuats̈ jtenats̈etayán; s̈os̈on acbe shecuats̈ muinÿnaná chcá mochanjobenay jtsayenam ${ }^{1}$. Hugo Jamioy Juagibioy}

10 Cuando las personas se acaban vuelven a la tierra", dijo el taita Arturo Jacanamejoy Mavisoy. Acabar es morir. Hay un último recorrido; el moribundo ya no es vivo, pero aún no es tierra y entonces recoge sus pasos. Vuelve y junta lo caminado para la muerte. Igual nada se lleva, quedan sus huellas. Vuelve a pisar y así avisa que ya se va, por eso los perros ladran a su paso y brillan los minacuros. También las hay desafortunadas, ánimas en pena, nunca terminan de recoger y mal aire son en el camino. Los caminos son lo que son porque los pisan, los que están vivos y los que no, los que estuvieron; son un lugar, son una reunión de vidas. Tal vez la vida sea el andar y la muerte la eternidad de las huellas, todo en el camino.

Tanguá benach es en camëntsá camino viejo, camino ancestral, camino milenario. Así se le llama al camino que comunica el Valle de Sibundoy con Mocoa, también al que lleva de Yunguillo al Valle, o de Mocoa a Yunguillo, a todos los que son camino viejo en el pie de monte amazónico del sur de Colombia. Existen estos caminos, cuentan los mayores, desde antes de la llegada de los misioneros, los colonos y las carreteras. Son, entre otras cosas, intercambio: de alimentos, de remedios, de saberes. Tejen la selva y las montañas siguiendo las huellas del agua. El río Mocoa, que nace cuando se juntan el río Titango (Manay en camëntsá) y el río Patoyaco al oriente del Valle de Sibundoy, junto con las quebradas que lo alimentan, son guías del camino viejo que comunica el Valle de Sibundoy y Mocoa (Imagen 1-2 y Fotografía 1). Imitando estos cauces va y viene tanguá benach, en descenso hacia las tierras bajas o en ascenso al Valle y al páramo de Bordoncillo.

\footnotetext{
Pon tus huellas

Se van cruzando

estos caminos

creados por tus abuelos;

son para encontrarse y darse la mano.

Pon tus huellas hijo,

así, seguirán viviendo.
} 


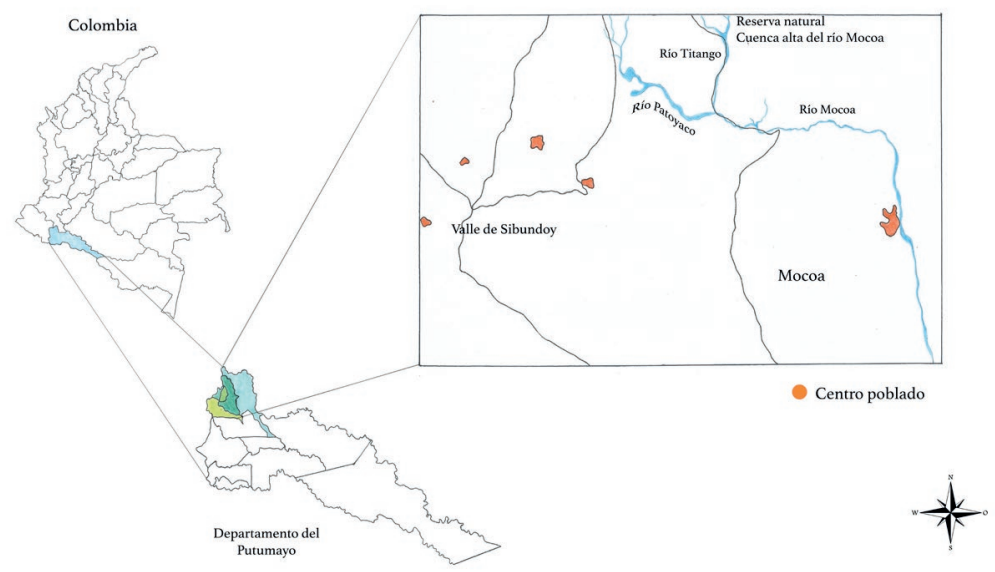

Imagen 1. Ubicación Valle de Sibundoy-Mocoa.

Fuente: Correa, Violeta (2020, Inédita).

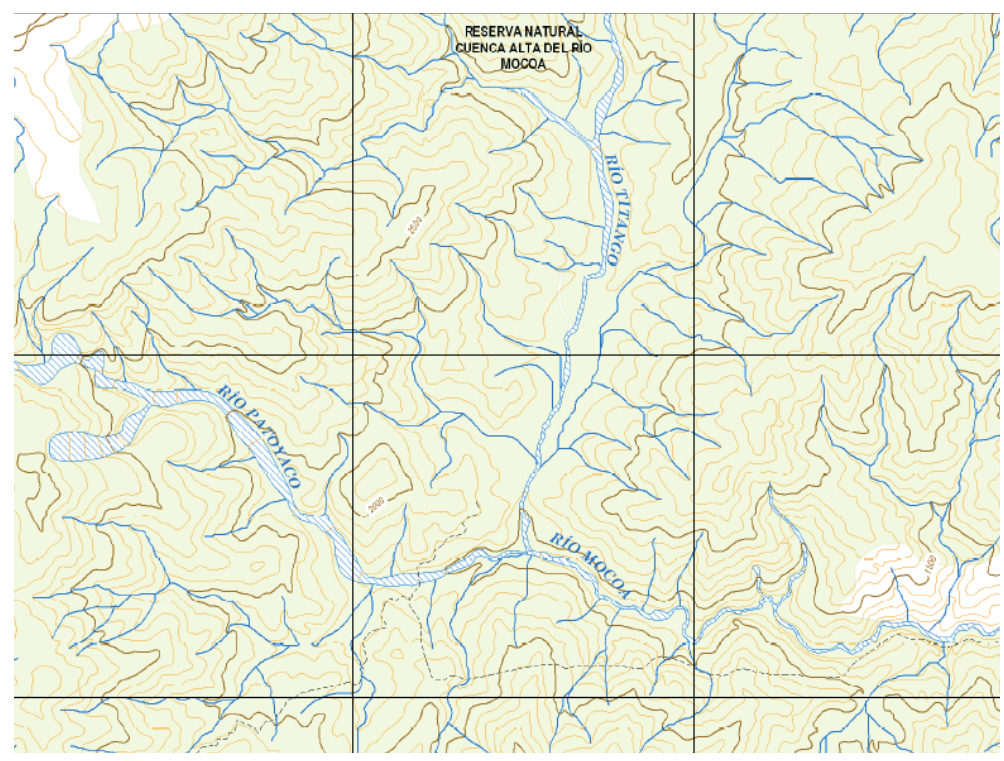

Imagen 2. Nacimiento del río Mocoa. Plancha Topográfica 430.

Fuente: SIGAG. 


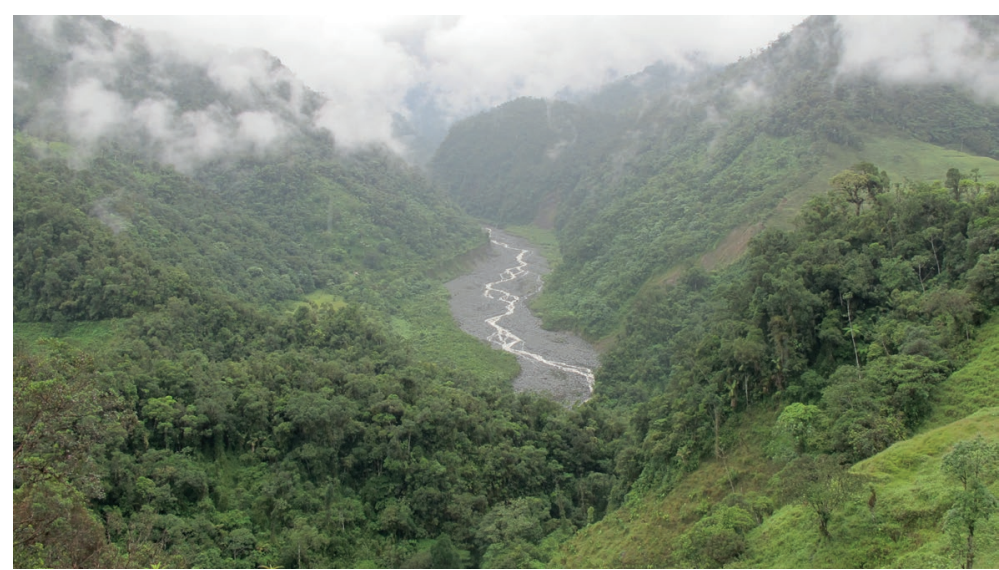

Fotografía 1. Río Playón, afluente del río Patoyaco.

Fuente: archivo de la autora.

Benach nombra al camino el pueblo Camëntsá. Los Camëntsá viven en Tabanok, que significa lugar de origen, también llamado Valle de Sibundoy en el departamento de Putumayo, Colombia. Tabanok se asienta en el antiguo lecho de una laguna, rodeado de montañas. Forma parte de la cuenca del río Putumayo, río que nace en el cerro Tortuga en las estribaciones de la cordillera de Portachuelo y sale por la garganta de Balsayaco, formada por el cañón del volcán Patascoy (Pinzón, Suárez y Garay, 2004). El anillo montañoso que rodea Tabanok está conformado por la cordillera Portachuelo al oriente, el cerro Cascabel al norte, y los volcanes Patascoy al sur y Bordoncillo al noroccidente (Jajoy, 2014).

Los Ingas también habitan el Valle de Sibundoy, que en inga se nombra Kindicocha, laguna del colibrí. Camëntsá e Inganos tienen comunicación con Sionas, Cofanes y Coreguajes, pueblos del bajo Putumayo; con Ingas que habitan en la Bota Caucana; y con los Pastos del departamento de Nariño. Estas relaciones, como los caminos que las sustentan, son ancestrales. Para la antropóloga María Clemencia Ramírez (1996), en el pie de monte se sintetiza el mundo andino y el selvático, ya que juega un papel fundamental en el establecimiento de intercambios y alianzas entre grupos andinos y amazónicos. La posición del Valle de Sibundoy lo determina como un corredor obligado entre las dos regiones. En el texto Mundos en red (Pinzón, Suárez y Garay, 2004) se afirma que los intercambios entre la selva y los andes no son exclusivamente comerciales, el Valle es un punto de articulación de los dominios chamánicos. Los Camëntsá y los Ingas andan la montaña y la selva, la síntesis o articulación de estos dos mundos no acontece exclusivamente en Tabanok, acontece, sobre todo, en los caminos y en cada uno de los caminantes que le dan vida a la ida y a la vuelta. 
Caminar es hacer memoria de los mayores al ir y volver, al volver a ir y devolverse ${ }^{2}$. "Los mayores siempre que iban hacia el bajo Putumayo hacían su ritual, su armonización, pidiéndole como permiso a la naturaleza para que los favorezca y volver", cuenta el taita Arturo Jacanamejoy (Comunicación personal, abril de 2018). Ancestras y ancestros han dejado el camino, ellos ya han recorrido, ya han caminado y han dejado sus huellas. Dejar significa soltar algo, retirarse o apartarse de algo o alguien, y al tiempo encargar, encomendar, poner algo al cuidado de alguien (Real Academia Española, s.f.). Tanguá benach son las huellas dejadas; andar es también saber pedir permiso para volver a pisar. Para los Guambianos (Dagua, Aranda y Vasco, 1998) el tiempo es como una rueda, que da una vuelta; es como un aro, que vuelve sobre sí mismo; así es el camino que marca el sol sobre la tierra. El tiempo va y vuelve, pasa y vuelve. El tiempo se repite y confluye con el presente en la medida en que sigue estando ahí y es escenario de la vida, como el territorio (pp. 63-64). Como benach. Caminar es hacer memoria con el consentimiento de Tsbatsanamamá, la madre tierra. Caminar es recordar, volver a pasar por el corazón lo que otros han dejado, lo que sigue estando ahí, a la vuelta.

Ainanocan significa en camëntsá todo aquello que se hace de corazón, desde el corazón. Esta palabra viene de ainán, corazón, y también de ain, aquello que tiene vida, que está vivo y lleno de energía. Para Tim Ingold (2018) el corazón y el ombligo son nudos, son el principio fundamental de coherencia: aquello que sujeta y mantiene en su lugar. Las mayoras Camëntsá cortaban el ombligo del recién nacido y lo enterraban junto a shachekbé, una de las piedras del shinÿac, el fogón, para asegurar que la persona recién llegada volviera a la tierra y que, en vida, honrara el legado de los ancestros. Además, así aseguraban que s̈os̈o, el bebé, creciera protegido, saludable, fuerte y con suerte. El corazón y el ombligo anudan a las personas con Tsbatsanamamá, con los y las que ya recogieron sus pasos, con lo que es, fue y será vida.

Aquello que está vivo lo está porque tiene energía. S̈buachana es el regalo de la tierra para alimentar ain. Maíz, fuerza, energía y esperanza, son la traducción de s̈buachana. "Taitang uabainëng ts̈aba juabnÿeng, los antiguos, mayores, ancestros Camëntsá con buen pensamiento, sabían decir que los granos de maíz que se siembran y se reproducen son los ojos de Dios", cuenta la bata ${ }^{3}$ Myriam Jacanamejoy (Comunicación personal, 
febrero de 2018). Los frutos, ts̈emats̈, choclo, y mats̈, maíz ${ }^{4}$, son fuerza, energía y esperanza; con ellos se prepara bocoy, chicha, uames̈nén, mote, bishán, sopa de maíz con coles, më̈quenan, colada, jangnëntsna, envueltos, torchén, arepas, guabsmacna, mote de choclo con frijol tranca, ts̈ëbonen, mazamorra y sangonán, sopa de maíz tostado. S̈buachana tiene misterio; sabe llorar, patear y reclamar, además de alimentar; es como la gente y sin s̈buachana no hay gente (Chaustre, 2019).

Tomar bocoytem, la chichita, permite que se camine, se baile y se celebre la vida. Anteriormente se hacía coronch bocoy, la chica de maíz juriado, floreado; se envolvía el maíz en hojas de achira y se ponía dentro de un canasto al lado del shinÿac por tres o cuatro días. El fuego abrigaba el maíz y lo hacía patear, le salían paticas ${ }^{5}$, se floreaba. Después de este proceso los mayores lo mascaban. Esa chicha quedaba dulcecita, así no más. Bien fuerte sí era. Aunque ya no se prepara así, se recuerda. Hoy se cocina el maíz molido en el fogón de leña y se pone panela para endulzar, después se junta con shëbuants̈, la guía o cuncho viejo. Shëbuants̈, aquello que queda de una chicha antigua, ya se fermentó, sabe, conoce la manera de dar fuerza y por eso guía; es el ancestro.

Para dar fuerza la chicha debe estar fuerte. La junta de s̈buachana, el calor del shinÿac, el cuncho viejo, y en algunos casos la saliva, animan, llenan el cuerpo de vida. Dice el taita Miguel Mavisoy que, en los caminos largos, pesados, no se debe tomar agua de las quebradas ya que se va la fuerza, el cuerpo queda débil y flojo; ni qué decir si se toma el jugo de una mandarina o de una naranja. Para el cansancio el mejor remedio es seguir andando y tomar bocoy, hija de s̈buachana, regalo de Tsbatsanamamá. También se toma chicha para bailar, que es una variación de caminar: zapatear, dar vueltas en un ir y venir sin ir para ningún lado. Durante el Betscnate 6 el cuerpo hace música, bailando y tocando se agradece la vida, la fuerza y la energía que permiten vivirla. Vida or joboijuama, ahora que hay vida bailemos y cantemos por nuestra existencia, saben versear.

Caminando y bailando se pisa la tierra, se toma ese pedacito de ella que es s̈buachana, se hace memoria de los ancestros. El camino se incorpora al caminante al pasar por su corazón y sus entrañas. A la vez, el

\footnotetext{
El choclo es el fruto de la primera cosecha, que se da seis meses después de sembrar. Maíz se llama al fruto más seco, que se da después de los siete u ocho meses de la siembra.

Paticas que son para andar.

El Betscnate o día grande, también conocido como Atun Puncha en Inga, Carnaval del Perdón, es la principal celebración entre los Camëntsá e Ingas ubicados en el Valle de Sibundoy. El lunes y martes previos al miércoles de ceniza, lunes entre Camëntsá y martes entre Ingas, se festeja el paso de un tiempo pasado a uno nuevo.
} 
caminante es camino. El derrumbo del indio da cuenta de cómo un caminante volcó en benach, lugar y palabra narrada:

Habían bajado un par de paisanos al bajo Putumayo llevando comida de lo frío a hacer intercambio con los del bajo Putumayo... habían llegando en la época del chontaduro, cuando había la producción de chontaduro en Mocoa. De allá habían traído chontaduro en canasto, sus seis, siete arrobas de chontaduro, cargado aquí, y salían de allá cargados. Y aquí en ese momento había estado bajando un derrumbo, bajaba el derrumbo, entonces uno de ellos que dijo, no, pues esperemos que baje el derrumbo, luego pasamos... el otro más atrevido disque que dijo, no, no, ya pasó, pasemos ya, cogió un bordón y disque comenzó a pasar. El otro más cobarde dique se quedó viéndolo a ver cómo iba adelante. Con el bordón comenzó a, caminando, caminando, cuando iba a mitad de camino vino la avalancha y lo agarró, lo envolvió y pues pobre canastico de chontaduros que iba dando vueltas, adiós. Entonces el otro como era Inga, y saben, ustedes saben como es el acento de ellos ¿no? Entonces que dijo, no, lastimita chontaduros. No le dio pena por el paisano sino más por el chontaduro [risas]. Entonces de allí le pusieron el nombre el derrumbo del indio. (Arturo Jacanamejoy Mavisoy, comunicación personal, abril de 2018)

Derrumbo, de rumbo. El atrevido rumbo de este caminante lo aterró, lo convirtió en monte, lo acabó, lo envolvió en tierra y agua que son sustancia del camino, de la vida y, como en este caso, de la muerte. Las avalanchas y los derrumbos son hacedores del camino, sus vueltas trazan; abrazan y reclaman las vidas que de la tierra son.

José María Arguedas (2014) describe el genio de Rasu-Ñiti, el que aplasta la nieve, un danzak. Wamani, el dios montaña que se presenta en forma de cóndor, es el espíritu que protege a Rasu-Ñiti; el hervor de la sangre del danzak durante las figuras en el baile y durante el toque de las tijeras depende de este espíritu, asentado en su cabeza y en su corazón. En la agonía de Rasu-Ñiti, Wamani se posa sobre su cabeza avisando la muerte. El danzak danza para partir, renace antes de morir. Mientras baila sus piernas se paralizan, después todo su cuerpo, porque el dios de la montaña se ha posado sobre su corazón reclamando su vida. Atok sayku, discípulo de Rasu-Ñiti, retoma la danza: “EEl Wamani aquí! ¡En mi cabeza! ¡En mi pecho, aleteando! -dijo el nuevo danzak" (p. 19). Rasu-Ñiti sigue allí, en la música de las tijeras y en los pies de su discípulo. Wamani es eterno, fuego y corriente de siglos aleteando. Danzak nunca muere. 
Wamani es montaña, wamani es cóndor, wamani es danzak. El danzak danza para partir como el caminante recoge sus pasos para morir. Tanto caminante como danzak son eternos, ancestros que vuelven en los pies de su descendencia; son montaña, ella hierve en su sangre y después los reclama; son duendes del camino.

Yo les voy a contar algo pues que me pasó a mí... mi abuela vivía para acá, pa donde vamos, en el Playón y una vez le traje una remesita allá, del peatonal ese hacia allá, hasta allá llegaba caballo. Entonces me llevó a mí, pa que le vaya llevando una remesita, mi maletica, y mi abuelo iba adelante, me dejó, yo me quedé pues, todo muchacho pues es inquieto, mirando así los pájaros, bueno, tanta cosa. Y pasé la primer cascada, había avanzado como unos metros, sentí que alguien me silbó de atrás, entonces ahí mismo voltié a ver, dije alguien viene atrás, entonces mi abuelo ya había cruzado, dio la vuelta, ya iba llegando a la otra cascada, seguí avanzando y me silbó nuevamente, y le volví a contestar, y miraba atrás y no miraba a nadie, hasta que llegué a la segunda chorrera, alcancé a pasar, pero ahí ya sentí como que, como que alguien me hubiera echado agua fría, me sentí como balfofo ya, y me silbó más cerquita. En ese momento comencé como a sentir algo diferente ya, ya como que no era el mismo camino, sino que ya el mismo duende me estaba ya como absorbiendo ya, a cambiarme la mente y la mirada, todo, la visión. Que si no se devuelve mi abuelo, hubiera parado por acá en la cascada. Esa, esas dos cascadas se unen acá, caen a una sola cascada grandísima, acá al río Titango, hay una playa...Y mi abuelo de ver que yo no llegaba vino y se devolvió, cuando él me habló, yo parecía que él me hablaba, ya, lo escuchaba pero ya lejos, yo ya me estaba ya como, como que el duende ya me estaba llevando por otro camino, porque el duende eso hace, lo llama, lo atrae y le muestra otro camino, este es el camino propio, pero le muestra otro, entonces por ahí puro monte, lo hace caminar en el aire, cuando se da cuenta ya es en, digamos al territorio de ellos, del duende, por eso le dicen la cascada del duende... Y luego por ejemplo por allí se perdían luego, eso eran tiempos, como era pura montaña, ahorita ya todo, hay cultivo, en cambio ese tiempo era pura selva, luego allá se perdía caballo y los encontraban acá en la chorrera, pero los encontraban la cola y la crin con hecho trenza o hecho nudo... Pero eso acá prácticamente ya como se fue poblando, como que eso poco a poco lo fueron corriendo, pero si de pronto alguien que le, como eso a cualquier humano le sale, eso hay personas que lo eligen, se pone ahí a perseguir y lo persigue y lo persigue... (Arturo Jacanamejoy Mavisoy, comunicación personal, abril de 2018) 
Esta narración la compartió el taita Arturo mientras pisábamos cerca de la chorrera del duende, no enfrente, de pronto la toreábamos. El duende es un espíritu del monte, de los lugares sagrados, lugares de vida como jatishñ, páramo, tjañ, montaña, uabjajonay, humedal y bejay, río. Estos lugares son pesados, tienen misterio y pueden enfermar, provocar mal aire. Por eso se les debe pedir permiso. El monte es el territorio del duende, allí vive, y como wamani él mismo es el monte. La montaña y la selva son su mundo, su visión, su mente y su camino, que a veces trata de imponer a otros caminantes. Actúa como guardián, cuida el territorio y despierta respeto al tiempo que temor.

Los indígenas de Tabanok que conocen y narran al duende no dan una descripción corporal, ya que no se presenta ante los ojos; se deja oler, sentir, escuchar, pero no ver. Es pícaro. Le gusta confundir y burlar al caminante que entra en su tierra o a quien se baña en sus aguas. Voltea el mundo. Cuando está cerca se hace escuchar lejos, riendo, silbando, tocando el rondador de tunda o llorando como un bebé, y cuando está lejos suena muy cerca. Deja ver sobre la tierra sus huellas, que son pequeños pies humanos, pero engaña, ya que camina en dirección contraria a la que señalan sus pisadas. Actúa como niño o niña que gusta de travesuras: a veces trenza el pelo de los caballos, hace música como si fuera carnaval, produce olor a flores o refunde las herramientas de trabajo.

El taita fue enduendado. Hay casos menos afortunados; hay quienes duran perdidos por horas, días; hay quienes son entregados al monte y nunca regresan; hay encantados y encantadas que pierden la mente, pasan horas junto al río, se escapan de su hogar en las noches para ir monte adentro, dejan de comer alimentos y se tragan la tierra, los invade la locura que algunos llaman amor, otros, embrujo. En "La duenda", Evelio Rosero (2018) describe poéticamente el enamoramiento de la duenda y un niño enduendado; este encuentro es perdición y remedio, ahogo y música. La persona que por el duende o la duenda es extraviada se olvida de sí misma. Enduendarse es la conciencia, ¿o el recuerdo?, de ser montaña y selva, de ser camino; es perderse para encontrarse; es ir y volver; es, a veces, solo ir.

El duende a algunos les regala el don de la música por medio de la tunda del monte con que se hacen las flautas y los rondadores. Como wamani, como s̈buachana, lo que entrega es un atributo. La fueteadora es una serpiente que da lastimando; ella no tiene veneno, pero su cola pega más duro que el látigo. Cuando fuetea a algún caminante lo deja herido, no obstante, al recuperarse, la persona adquiere el don de la velocidad. Se dice que quien ha sido tocado por la gracia de la fueteadora 
no es alcanzado nunca en los caminos. Estos espíritus de Tsbatsanamamá entregan cualidades a la gente, regalos que amarran, anudan; atribuir es también poseer. Saber corresponder a estos regalos es mantener la armonía.

En camëntsá dicen Juabayán, Juabayán es como bendecirlo con alguna imagen, y de ahí nace la idea de colocar una imagencita... y hasta el momento fíjese que uno pasa por debajo de las piedras y no se ha deslizado nada, quedó como pagado, es como una forma de como motivar digamos la, cómo le digo, las avalanchas, tragedias, una forma de digamos desde el pensamiento indígena, hacer que se evite todo eso... yo cuando antes, cada vez que yo venía, cuando estaba la imagencita allí, ahorita pues solamente mi pensamiento no más... entonces siempre le pedía a la imagen, para cuando yo iba para el Paraíso, siempre yo colocaba una velita allí, y de regreso también traía otra velita, dejaba prendiendo, pues como agradeciendo a la virgen y a la misma naturaleza porque me permite ir y volver. (Arturo Jacanamejoy Mavisoy, comunicación personal, abril de 2018)

Juabayán traduce poner nombre, bautizar (Bautista-Jacanamijoy, 2018). El taita narra sobre una imagen de la virgen que estaba en tanguá benach, pero que se robaron. En su momento, al poner la imagen quedó pagado, se hizo una ofrenda para evitar avalanchas y derrumbos, tragedias. "Uno pasa por debajo de las piedras y no se ha deslizado nada", las piedras son quienes están en armonía, quietas, tranquilas. Las imágenes católicas son muy significativas para los indígenas Camëntsá, pero no se sostienen sin las piedras. La virgen llegó con los colonizadores, las lajas son eternas. Las piedras tienen espíritu y son sagradas, no en vano la virgen de las lajas es considerada milagrosa. "Las piedras son el lecho del mundo mismo...el mundo es una piedra primordial que pare piedras que paren piedras y todas viven a un ritmo tan lento que no las vemos vivir y por la brevedad de nuestras vidas algunos creemos que están muertas" nos dice Arturo Balbuena (2016, p. 12). Las piedras son camino, son río, son mina y barranco, son cuarzo, el rayo en la tierra (Chaustre, 2019). A las piedras, a la virgen que bautiza y a la naturaleza misma se ofrenda el fuego, se pide la bendición para ir y volver ${ }^{7}$, se agradece.

El movimiento de las piedras quiere decir algo. Los derrumbos y las avalanchas avisan, dice la bata Esperanza Jacanamejoy. Estas señales son la voz de Tsbatsanamamá: en Mocoa sucedió una tragedia el primero

"Bendición mamita", "bendición padrino", "bendición abuelita”; es la forma en que los niños y niñas saludan a sus mayores. 
de abril de 2017, una avalancha acabó con más de 300 personas y se llevó varios barrios tras el desbordamiento del río Sangoyaco, el río Mocoa y el río Mulato (El Espectador, 2017). Esta desgracia estaba anunciada, las exploraciones y excavaciones mineras que se vienen realizando en la cuenca alta del río Mocoa han removido tierra sin permiso, y ella agarró camino río abajo. Grandes empresas extranjeras quieren tomar riquezas, sin consentimiento ni correspondencia, maltratando el camino, a quienes lo caminaron y lo caminan.

La costumbre de ocupar para tomar es en gran medida herencia de la avanzada conquistadora y evangelizadora, que llegó a Tabanok en 1535, cuando arribaron al Valle Juan de Ampudia y Pedro de Añasco, lugartenientes de Sebastián de Benalcázar (Bonilla, 1969). María Clemencia Ramírez (1996) señala que el objetivo primordial de las expediciones de los españoles en la selva amazónica era la búsqueda de minas de oro. Se suponía que El Dorado, ciudad fabulosa, estaba en algún lugar de la selva, al oriente de las ciudades andinas de Quito y Pasto, en un área bordeada por los ríos Napo, Putumayo y Caquetá (Taussig, 2012, p. 354). Nombrar, asentar y agrupar poblaciones indígenas fue la estrategia para conquistar el pie de monte amazónico; Mocoa y Ecija de los Sucumbíos se instauraron como nuevos poblados en la selva a mediados del siglo XVI para explotar el oro de los ríos Cascabel y la Bermeja (Bonilla, 1969). En estos ordenados lugares de existencia se controló y vinculó mano de obra indígena a procesos extractivos.

La mayoría de expedicionarios nombrados s̈quená, personas blancas, no indígenas, de afuera, no han sabido pedir permiso al volver a pisar. Creen que llegan a tierra virgen. Carlos Páramo Bonilla (2018) señala que el misionero y el conquistador siempre son él, en masculino; él descubre, desnuda, busca desflorar y poseer la selva, la América indígena fantaseada como una voluptuosa mujer aindiada, medio amazona, medio virgen (p. 15). Los expedicionarios, aún hoy, no piden el favor de los antiguos porque no los reconocen como la huella que son. El consentimiento de Tsbatsanamamá depende de una actitud del caminante; quien sabe honrar a los mayores trata de sentir, la tierra, el agua, la piedra, lo que otros han dejado; trata de sentir lo que contiene el camino y al tiempo a sí mismo, al andar. Pedir permiso entonces es saberse de la tierra, si algo de ella se toma hay que dar algo para mantener la armonía.

Cuando se toma chicha se brinda. Quemëjua nÿets capamillang, salud con todos, se dice y se ofrenda un sorbo a la tierra. La chicha se distribuye en botijas de tres o cuatro litros con un vaso, para compartir la medida individual. El botijero tiene la tarea de repartir y comienza diciendo en voz 
alta, para ser atendido, quemëjua nÿets capamillang. Si pasa por alto este acto corre el riesgo de terminar muy borracho, ya que a cada persona a la que le brinde le responderá: sírvase, y deberá tomar en varias ocasiones durante la ronda. Ronda que inicia ofrendando a la tierra. Ronda que lleva un orden para no dejar a nadie sin beber. Ronda que se repite y multiplica ya que hay, a la vez, varias personas brindando. Ronda que va y vuelve, así marea, vuelca a los tomadores. Cuando se toma, por más borracho que se esté, se debe brindar y ofrendar.

Los conquistadores utilizaron tanguá benach para acceder a la selva y a las montañas, transitaron el camino antiguo y con él se encontraron. Hernán Pérez de Quesada, en el siglo XVI, dijo sobre esta tierra que era como las gentes que la habitaban, engañosa, inaccesible, hostil, desconocida, generadora de malos humores, que enfermaba a los españoles en razón de su mala constelación; tierra donde los tigres y los caimanes eran tan atrevidos como los que mandaban las flechas envenenadas con plantas (Pinzón, Suárez y Garay, 2004, p. 61). Fray Fidel de Montclar, misionero capuchino, escribió en el siglo XX:

Una casi infranqueable barrera de altísimas montañas separaba del resto de Colombia el vasto territorio... La senda que comunicaba aquel mundo salvaje con el civilizado era lo más original y horroroso que pueda uno imaginarse; diríase que algún espíritu maléfico se había entretenido en distribuir precipicios y despeñaderos para impedir la entrada en aquellas soledades, donde el salvajismo vegetaba a sus anchas. (Citado en Ramírez, 1996, p. 119)

Tsbatsanamamá, dejan claro los testimonios, no es para estos conquistadores su madre tierra, no están a ella anudados. Suponían únicamente transitar el camino, pasar sobre esta tierra. Ingold (2018) en sus reflexiones sobre la superficie dice que creemos vivir sobre la tierra y no en ella, como esperamos que las plantas crezcan sobre el suelo y no en él. Pero una de las características de la superficie es que sufre una continua generación, es decir, no es preexistente; esta es su capacidad de nutrir la vida (p. 72). El camino es la gente que le da vida al incorporarlo en cada paso, al tomar y dar algo. A pesar de negarse a ser parte de esta tierra, si es que la caminaron, las huellas de los expedicionarios también son camino.

Hasta principios del siglo XX el Valle de Sibundoy y sus caminos fueron transitados de manera intermitente por misioneros y colonos. La frontera misionera coincide con la frontera minera: mientras lograban explotar las riquezas minerales, los curas permanecían en la zona 
realizando funciones religiosas, judiciales y gubernamentales. Pero dicha frontera estaba en constante movimiento. Con el cese de la extracción de oro a principios del siglo XIX, los franciscanos abandonaron los pueblos del Putumayo después de más de cien años de colonización (Ramírez, 1996). Durante las luchas por la independencia el suroccidente colombiano fue olvidado por carecer de importancia política y militar; desaparecieron entonces los funcionarios y curas que solían dejar noticias sobre esos territorios (Bonilla, 1969). Es en 1899 cuando los capuchinos renuevan la vida de las misiones en la región; el estado colombiano, sin herramientas para gobernar todos sus territorios, delega a misioneros católicos la "administración" de los indios, designados jurídicamente como salvajes (Gómez, 2005).

La llegada de los frailes capuchinos a Tabanok coincide con el auge extractivo del caucho en el Bajo Putumayo. Hombres católicos, s̈quená, se establecen en el Valle con la intención de administrar, organizar, disponer y ordenar este mundo, a partir de su mirada y su forma de caminar. De movilizarse más bien, ya que estos misioneros acostumbraban transitar sobre otros: caballos, mulas y cargueros. Michael Taussig (2012) señala que los caminos indios no estaban hechos para caballos y mulas, con su paso se convertían en lodazales impasables; por esto el cargador indio fue utilizado como transporte terrestre en los Andes. A pesar de la ordenanza del siglo XVI que prohibía el uso de cargueros (Ramírez, 1996), entrado el siglo XX los misioneros capuchinos seguían desplazándose a lomo de indio (Taussig, 2012).

El taita Marcelino Chicunque dice que la huella son los pieses que han dejado pisando. Los pies nunca son los de entonces (Suárez-Guava, 2003). En los callos está el tiempo. Al montarse sobre un carguero los pies de los misioneros eludían su labor, estaban sin estar. Su incapacidad de poner huella los sometía al indígena: era extremadamente mortificante la dependencia del sillero y de los cargueros, quienes tenían los amos a su merced (Taussig 2012, p. 362). El carguero llevó a cuestas al misionero y a las riquezas explotadas: "los indios afirman que sus abuelos cargaban por los Andes, desde la cuenca amazónica hasta Pasto, pesos de hasta doscientas libras de caucho" (p. 364). Los pies indígenas soportaron la construcción de un mundo industrial, mundo que se transita por carreteras, no se vive en caminos; en él se pone a rodar el caucho.

Los proyectos extractivos, aquellos que desnudan y poseen la tierra de forma violenta, necesitan tanto de vías de comunicación como de manos y pies de obra. A principios del siglo XX se crea la prefectura apostólica del Caquetá y Putumayo; el fraile prefecto Fidel Montclar le propone 
al estado abrir un camino para articular los centros misionales de Mocoa y Sibundoy con Pasto. Esta idea es apoyada por el entonces presidente Rafael Reyes (1904-1909), quien tuvo una estrecha relación con el comercio y la extracción de quina del Bajo Putumayo, algunas décadas atrás. Se necesitaba saltar la "infranqueable barrera de altísimas montañas" para tener acceso al Putumayo, el nuevo Dorado de la extracción. Hacia 1912 se inaugura la carretera Pasto-Mocoa, que atraviesa Tabanok; esta permitió transitar la vía sobre caballos, hoy en día en camionetas. Los misioneros se atribuyen este trabajo, negando la mano de obra gratuita, esclavizada, de los indígenas de Tabanok.

La apertura del nuevo camino significó la afirmación de la extracción: de 1900 a 1946 hubo expediciones ligadas a la extracción de caucho; entre 1963 y 1976 fue la fiebre petrolera, precedida por la explotación de madera desde 1950 y el comercio de pieles desde 1960; a partir de 1977 llega y se expande el cultivo de la coca (CNMH, 2015). Estos procesos se sustentan en una acción: tomar, tomar sin medida ni consentimiento, tomar sin permiso ni reciprocidad. Ingold (2015) habla de las líneas de ocupación, una red de conexiones que se imponen al tejido de los senderos, como si el territorio ocupado fuera una superficie en blanco. Estas líneas facilitan el paso de personal y material a los lugares de asentamiento y explotación, así como la extracción de las riquezas de los mismos (p. 121). Surge, desde principios del siglo XX, una tensión entre la carretera que se trata de imponer y la resistencia de los pies indígenas, que vuelven a pasar por el corazón los pasos de los ancestros al caminar tanguá benach.

Las líneas de ocupación tienen un efecto sobre el lugar, entendido en la modernidad como un nexo que contiene la vida, como un punto de unión (Ingold, 2015, p. 139). La estrategia de establecer pueblos y caseríos en donde se reunía a los "salvajes" persistió durante la primera mitad del siglo XX en el Putumayo y, en general, en los territorios amazónicos y de frontera. Se suponía que, de permanecer dispersos en los montes, los indígenas no prestarían ningún servicio al municipio, a la misión, al comercio, ni al "progreso" (Gómez, 2005, p. 57). Concentrar la vida, evitar al caminante caminar, es una forma de dominar. En el capítulo "Los viajes" de Los ríos profundos Arguedas (2009) nos describe el lugar como todo lo que queda en el recuerdo del caminante, ainanocan para los Camëntsá: el lugar es un río, una quebrada, sus piedras lúcidas y peces menudos, los remansos, las cascadas, los remolinos, los vados, las aguas que reflejan las montañas, el sonido del río; el lugar es un árbol, un nido de pájaro; es el pájaro, su vuelo, su canto, su dirección; el lugar es el viento; el lugar son los campos sembrados, los montes, los cerros, las faldas de la montaña; el lugar es el croar de los sapos; el lugar es sus gentes. 
Tanguá benach es lugar: camino; pasos; lo que es, fue y será vida; lo que da vida; s̈buachana y chicha; recuerdo; huella; quien camina y quien baila; pícaro duende; música; pies, ombligo, corazón y manos; guía; Tsbatsanamamá, madre tierra; la ida y la vuelta; monte; atributo; ancestros y ancestras; palabra; quien brinda; devuélvase; avalancha y derrumbo; montaña y selva; espíritu; río y piedra; la ofrenda; reunión de vidas y andares; el principio y el final; muerte y vida; lo eterno.

La preocupación por abrir camino monte adentro hoy persiste. En el año 2012 inició la construcción de la variante San FranciscoMocoa del eje Amazonas-IIRSA ${ }^{8}$, un trazado de $45 \mathrm{~km}$. Este proyecto no realizó la consulta previa entre los pueblos Inga y Camëntsá, habitantes ancestrales del territorio. Un año atrás, en el 2011, el departamento de Putumayo había sido declarado distrito minero, destinándolo a la explotación de minerales ${ }^{9}$. Este trazo, esta carretera planeada, no se ha logrado construir. Tanguá benach percibe cuando no hay reciprocidad. Al sentirse irrespetado por caminantes que no saben pedir permiso, no reconocen las huellas, no corresponden a la tierra sus dones, reacciona; tranca y dificulta el paso, enferma, genera malos humores, malos aires. Las avalanchas y los derrumbos son manifestaciones de la fuerza de la tierra, que reclama aquello que le pertenece y marca su senda, expresa su voluntad. Desde hace cuatro años la obra de la variante está abandonada "por falta de planificación" (Noticias Caracol, 2019), porque se han robado mucho dinero, pero, sobre todo, porque la tierra se vuelca una y otra vez sobre las líneas de cemento.

La actividad minera y los proyectos de infraestructura, que buscan asegurar el tránsito de recursos naturales desde el interior de las selvas de Colombia a los principales centros de producción y consumo del mundo, amenazan sobre todo las cuencas hidrográficas, la vida. Sin agua no existe tanguá benach, ella es la guía. Susunga quiere decir en inga recoger algo en la mano, como cuando uno va a recibir algo y abre la mano. El río Susunga es aquel que viene recogiendo todas las aguas de la cordillera Tortuga y va a dar al río Mocoa, que lo recoge. Todos los ríos son susunga, manos

\footnotetext{
La Iniciativa para la Integración de la Infraestructura Regional Suramericana, que pertenece hoy al Consejo Suramericano de Infraestructura y Planeamiento (COSIPLAN), es un plan estratégico adoptado desde el año 2000 por 12 Estados Suramericanos, para potenciar el desarrollo económico de la región. Los principales proponentes y prestamistas de esta iniciativa son el BID y la CAF. Bajo esta bandera se conforman 593 proyectos de inversión en tres sectores: transporte, energía y telecomunicaciones. Esta iniciativa propone la adecuación y construcción de diez ejes de conexión terrestres y fluviales, que atraviesan las regiones con mayor cantidad de recursos naturales no renovables (Jajoy, Villamil y Barrera, 2013).

Entre Mocoa y San Francisco hay centros de explotación de oro en veta y de molibdeno; otros potenciales mineros en el territorio, de interés para las empresas, son el cobre, el níquel, el plomo, la plata, el zinc, el platino y asociados, materiales de construcción, calizas y mármoles (Pardo, 2015).
} 
que recogen; son la junta de las aguas como los caminos son la junta de los pasos. "Se van cruzando estos caminos creados por tus abuelos; son para encontrarse y darse la mano", escribe Hugo Jamioy (2010, p. 83); dar o prestar la mano es hacer con otros, juntarse, recoger y compartir conocimiento, existencia, trabajo; es brindar, ofrecer y celebrar la vida; es ser Cabënga, nosotros mismos (Chaustre, 2019).

Empezaron a hacer el dragado y muchos mayores y mayoras lloraban: "cómo se les ocurre mover la tierrita, ¿qué irá a pasar?" Y los mayorcitos decían, "de pronto nosotros no vamos a sentir, nosotros ya nos vamos de aquí, pero..." y yo era pequeño, tenía mis hermanitas, nos abrazaba y nos decía, "mijito, mijitos van a sentir, van a sufrir, porque comenzaron a mover la tierra, comenzaron a mover lo que no tienen que mover..." (Arturo Jacanamejoy Mavisoy, comunicación personal, abril de 2018)

Dragar es imponer un nuevo rumbo al río, transformar su senda. Dragar es mover lo que no se tiene que mover. Una de las estrategias del Instituto Colombiano de Reforma Agraria para adecuar las tierras del Valle de Sibundoy a la agricultura intensiva en la década de los 60, fue dragar algunos ríos y quebradas. Esto ha tenido consecuencias; las aguas buscan su cauce y se llevan lo que se les atraviesa. Hay zonas del Valle que se inundan con frecuencia, recuerdan que son huella de una laguna y de agua se llenan. El camino ancestral, como el río, anda, sigue su rumbo. La importancia de los rituales aprendidos de los mayores para el camino, para la vida, es pedir consentimiento y tratar de evitar las tragedias; hacer el esfuerzo por sentir con los otros, los que ya no están y los que al lado caminan. En este diálogo con la madre tierra, los ancestros y sus pasos, se vuelve a pasar por el corazón, ainanocan; se afirma la vida y la muerte, correspondencia arquetípica.

"¿Pa qué los indios quieren más tierra?, tienen tierra y ni trabajan, todo tienen montaña", comenta Arturo Jacanamejoy que se preguntan los colonos sobre los procesos de titulación de resguardo, y continúa: "piensan que el indio necesita esa tierra es para explotarla". La defensa de la tierra, de tanguá benach, es la defensa de la vida, de la existencia, del agua. No es la defensa de una posesión. Este caminar, como las pisadas del duende, es engañoso y no siempre coherente. Devuélvase. Recuerde de dónde viene y que para allá va, porque, como el duende, cuando va viene. Si da vida, vida da. Los ancestros vuelven, no los niegue.

Uno mismo es el territorio. Nosotros somos de carne, hueso y tierra. La madre tierra es el territorio. Nosotros somos el territorio. 
Tenemos que valorar y darle fuerza a la tierra; si nosotros morimos y nos entierran en la tierra, o sembramos matas ahí, cría con más fuerza. (Marcelino Chicunque, mientras hacía un ritual; pedía permiso de caminar tanguá benach. Comunicación personal, abril de 2018)

\section{Cuando las personas se acaban vuelven a la tierra.}

\section{Referencias bibliográficas}

Arguedas, J. M. (2009). Los ríos profundos. Argentina: Losada.

Arguedas, J. M. (2014). La agonía de Rasu-Ñiti. En J.M. Arguedas, La agonía de Rasu-Ñiti y otros cuentos (pp. 7-20). Santiago de Chile: LOM.

Balbuena, A. (2016). Casi todas las piedras o de la edad del mundo. Mala gana (26), 9-12.

Bautista-Jacanamijoy, J. (Comp). (2018). Diccionario Bilingüe: Camënts̈á: Español, Español: Camënts̈á. Sibundoy, Putumayo: SIL International. Recuperado de https://www.sil. org/resources/archives/73123

Bonilla, V.D. (1969). Siervos de dios y amos de indios. El estado y la misión capuchina en el Putumayo. Bogotá: Editado por el autor.

Chaustre, L. (2019). Vida or joboijuama. Ahora que hay vida bailemos y cantemos por nuestra existencia: la risa entre los Camënẗ̈á (tesis de maestría). Facultad Latinoamericana de Ciencias Sociales, Ecuador.

Centro Nacional de Memoria Histórica (CNMH). (2015). Petróleo, coca, despojo territorial y organización social en Putumayo. Bogotá: CNMH.

Dagua, H., Aranda, A.M. y Vasco, L.G. (1998). Guambianos. Hijos del arcoiris y del agua. Bogotá: Los cuatro elementos.

El Espectador. (27 de diciembre 2017). Avalancha en Mocoa, una de las peores tragedias de 2017. El Espectador. https://www.elespectador.com/noticias/nacional/avalanchaen-mocoa-una-de-las-peores-tragedias-de-2017-articulo-730617

Gómez, A.J. (2005). El Valle de Sibundoy: el despojo de una heredad. Los dispositivos ideológicos, disciplinarios y morales de dominación. Anuario Colombiano de Historia Social y de la Cultura (30), 51-73.

Ingold, T. (2015). Líneas. Una breve historia. Barcelona: Gedisa.

Ingold, T. (2018). La vida de las líneas. Santiago de Chile: Ediciones Universidad Alberto Hurtado.

Jajoy, P. (2014). Iuiari- Jten Inyenam. Memoria y reencuentro en el territorio (tesis de pregrado). Universidad de Nariño, Colombia.

Jajoy, P., Villamil, J. y Barrera, M. (2013). La intervención estatal y privada en el Valle de Sibundoy - Región Alto Putumayo y sus impactos en las comunidades indígenas inga y kamëntsá. Rostros y rastros (10), 83-91.

Jamioy, H. (2010). Bínÿbe oboyejuayëng. Danzantes del viento. Colombia: Ministerio de Cultura. 
Noticias Caracol. (15 de diciembre, 2019). Variante San Francisco-Mocoa, obra de más de 20 años que pasó de "elefante a mamut blanco". Noticias Caracol. Recuperado de https://noticias.caracoltv.com/colombia/nacional/variante-san-francisco-mocoaobra-de-mas-de-20-anos-que-paso-de-elefante-mamut-blanco

Páramo-Bonilla, C.G. (2018). Introducción: Un oficio que tiene chiste. En C.G. PáramoBonilla (comp.), Sal de la tierra: Misiones y misioneros en Colombia. Siglos XIX - XXI (pp. 13-43). Bogotá: Instituto Colombiano de Antropología e Historia (ICANH).

Pardo, A. (2015). Del discurso del desarrollo al Buen vivir: Una aproximación con enfoque étnico diferencial a la intervención megaminera en el Alto Putumayo (tesis de pregrado). Universidad Colegio Mayor de Nuestra Señora del Rosario, Bogotá, Colombia.

Pinzón, C., Suárez, R. y Garay, R. (2004). Mundos en red. La cultura popular frente a los retos del siglo XXI. Bogotá: Universidad Nacional de Colombia

Real Academia Española. (s.f.). Dejar. En Diccionario de la lengua española. Recuperado de https://dle.rae.es/?w=dejar

Ramírez, M.C. (1996). Frontera fluida entre Andes, piedemonte y selva: el caso del Valle de Sibundoy, siglos XVI-XVIII. Bogotá: Instituto Colombiano de Cultura Hispánica.

Rosero, E. (2018). La duenda. Colombia: Loqueleo.

Suárez-Guava, L.A. (2003). El tiempo entre los inga de Bogotá. Bogotá: Universidad Nacional de Colombia.

Taussig, M. (2012). Chamanismo, colonialismo y el hombre salvaje: un estudio sobre el terror y la curación. Colombia: Editorial Universidad del Cauca. 